\title{
NOTE
}

\section{Fluorescent probes as a tool for labelling and tracking the amphibian chytrid fungus Batrachochytrium dendrobatidis}

\author{
Sarah M. Herbert ${ }^{1,2, *}$, Tommy L. F. Leung ${ }^{1,3}$, Phillip J. Bishop ${ }^{1}$ \\ ${ }^{1}$ Department of Zoology, University of Otago, Dunedin 9016, New Zealand \\ ${ }^{2}$ Present address: EcoGecko Consultants Ltd, Wellington 6012, New Zealand \\ ${ }^{3}$ Present address: Zoology, School of Environmental and Rural Science, University of New England, Armidale, \\ New South Wales 2351, Australia
}

\begin{abstract}
The dissemination of the virulent pathogen Batrachochytrium dendrobatidis (Bd) has contributed to the decline and extinction of many amphibian species worldwide. Several different strains have been identified, some of which are sympatric. Interactions between co-infecting strains of a pathogen can have significant influences on disease epidemiology and evolution; therefore the dynamics of multi-strain infections is an important area of research. We stained $B d$ cells with 2 fluorescent BODIPY ${ }^{\circledR}$ fatty acid probes to determine whether these can potentially be used to distinguish and track $B d$ cell lines in multi-strain experiments. $B d$ cells in broth culture were stained with 5 concentrations of green-fluorescent BODIPY FL and red-fluorescent BODIPY 558/568 and visualised under an epifluorescent microscope for up to $16 \mathrm{~d}$ post-dye. Dyed strains were also assessed for growth inhibition. The most effective concentration for both dyes was $10 \mu \mathrm{M}$. This concentration of dye produced strong fluorescence for 12 to $16 \mathrm{~d}$ in $B d$ cultures held at $23^{\circ} \mathrm{C}$ ( 3 to 4 generations), and did not inhibit $B d$ growth. Cells dyed with BODIPY FL and BODIPY 558/568 can be distinguished from each other on the basis of their fluorescence characteristics. Therefore, it is likely that this technique will be useful for research into multi-strain dynamics of $B d$ infections.
\end{abstract}

KEY WORDS: Amphibian chytrid fungus - Batrachochytrium dendrobatidis · Epifluorescence microscopy $\cdot$ Co-infection $\cdot$ BODIPY FL $\cdot$ BODIPY 558/568

\section{INTRODUCTION}

An individual host can often be infected with many different strains of the same parasite (Read \& Taylor 2001, Lagrue et al. 2007, Leung et al. 2009). Coinfecting strains can sometimes interact (directly or indirectly), and the outcome of these interactions can either be antagonistic, commensal, or mutually beneficial (Massey et al. 2004, de Roode et al. 2005, Råberg et al. 2006, Buckling \& Brockhurst 2008). The nature of such interactions can shape the epidemiology and evolution of the pathogen and the resulting pathology for the host (Read \& Taylor 2001). For example, intraspe- cific competition between malaria strains Plasmodium chaubaudi favours the most virulent strain, resulting in more severe pathology for the host (de Roode et al. 2005, Bell et al. 2006). Conversely, interference competition between co-infecting bacteriocin-producing bacterial strains results in a decrease in disease severity (Massey et al. 2004). Therefore, identifying the type of interactions between co-infecting strains is an important area of research for the study of infectious diseases.

Batrachochytrium dendrobatidis $(B d)$ is a highly virulent fungal pathogen of amphibians that has been implicated in the decline or extinction of more than 200 
amphibian species over the past 4 decades (Skerratt et al. 2007). $B d$ parasitises keratinised areas of amphibian skin, inhibiting ion transport across the epidermis and causing host death by cardiac failure resulting from electrolyte depletion (Berger et al. 1998, Marantelli et al. 2004, Voyles et al. 2009). While geographically disparate strains of $B d$ display very little genetic variation (Morehouse et al. 2003, James et al. 2009), recent studies found that genotypically distinct strains exist, and they vary in morphology, growth, and virulence (Berger et al. 2005b, Fisher et al. 2009). Bd has been spreading rapidly around the globe (Morehouse et al. 2003, James et al. 2009). It has been introduced on multiple occasions into South America (Lips et al. 2008) and several distinct strains exist in Japan (Goka et al. 2009) and on the Iberian Peninsula (Walker et al. 2010). Therefore, it is possible that amphibians can become co-infected with more than one strain of $\mathrm{Bd}$. However, nothing is known about how co-occurring $B d$ strains may interact with each other.

In order to investigate the dynamics of multi-strain infections, one must be able to reliably discriminate between strains. At present, $B d$ strains can be distinguished by genotype, proteomics, and zoosporangia morphology (Morgan et al. 2007, Fisher et al. 2009). In the present study, we demonstrate that fluorescent probes can be used to label and track live $B d$ cells. Heritable fluorescent labelling could be useful for locating $B d$ cells, determining growth and zoospore production, as well as for providing a means to conveniently distinguish strains. Fluorescent probes have been used successfully for tracking metazoan parasites (Kurtz et al. 2002, Keeney et al. 2008, Leung et al. 2010) and for examining $B d$ growth, physiology, anatomy, and viability (Weldon 2005, Stockwell et al. 2010). In the present study, we trialled BODIPY ${ }^{\circledR}$ fatty acid analogue probes (Molecular Probes, Invitrogen) for labelling $B d$ cells. In order to determine if the BODIPY probes are suitable for tracking different $B d$ cell lines, we investigated the heritability and longevity of fluorescence, whether $B d$ cells can be discriminated by their label, and if the probes inhibited $B d$ growth.

\section{MATERIALS AND METHODS}

Chytrid culture. Bd type isolate JEL197 (Longcore et al. 1999) was sourced from a cryo-archived culture held by R. Poulter and M. Butler, Department of Biochemistry, University of Otago, New Zealand, and thawed as described by Boyle et al. (2003). Bd was grown on $1 \%$ tryptone-agar plates (T-plates) at $23^{\circ} \mathrm{C}$ for $7 \mathrm{~d}$ prior to staining. Prior to experimentation with the dyes, cells were examined under a range of Olym- pus BX51 epifluorescent microscope filters to determine autofluorescence.

Staining procedure. Protocols were adapted from the manufacturer's instructions for dyeing cells with CellTracker probes (Molecular Probes 2008). Upon receipt, the dyes were dissolved in dimethyl sulfoxide (DMSO) to a concentration of $100 \mu \mathrm{M}$ and stored in the dark at $-20^{\circ} \mathrm{C}$. Zoospores were harvested from T-plates by flushing with $6 \mathrm{ml} 1 \%$ tryptone broth (T-broth) and counted using a haemocytometer. The resulting $\mathrm{T}$ broth and zoospore mixture was placed into $1.5 \mathrm{ml}$ tubes as $1 \mathrm{ml}$ aliquots. The tubes were centrifuged for $15 \mathrm{~min}$ at $664 \times g$ to pellet cells, and the top $950 \mu \mathrm{l}$ of supernatant was removed. The dyes were diluted from the $100 \mu \mathrm{M}$ stock solution to make double the desired concentration in T-broth. Fifty $\mu$ l of this $2 \times$ concentrated dye mixture were added to the remaining $50 \mu \mathrm{l}$ of $B d$ broth culture in each tube, resulting in the zoospores being suspended in the desired concentration of dye. The cultures were protected from light and incubated at 20 to $23^{\circ} \mathrm{C}$ for $1.5 \mathrm{~h}$. After incubation, the cells were washed by adding $950 \mu$ l of T-broth, centrifuging again, then removing the top $950 \mu$ of broth and replacing with $1 \mathrm{ml}$ of fresh T-broth. This procedure yielded on average a $71.11 \pm 6.19 \%( \pm \mathrm{SE})(\mathrm{n}=4$ post-dye cultures) pure culture of zoospores in $1.05 \mathrm{ml}$ broth at about half of the originally harvested zoospore concentration. The remaining $28.89 \%$ of cells in the dyed cultures consisted of zoosporangia and thalli. Five concentrations of the red-fluorescent BODIPY 558/568 $\mathrm{C}_{12}$ (excitation wavelength [ex]: $559 \mathrm{~nm}$, emission wavelength [em]: $568 \mathrm{~nm}$ ) and the green-fluorescent BODIPY FL $\mathrm{C}_{12}$ (ex: $505 \mathrm{~nm}$, em: $511 \mathrm{~nm}$ ) dyes were trialled: $0.1 \mu \mathrm{M}, 0.2 \mu \mathrm{M}, 2 \mu \mathrm{M}, 10 \mu \mathrm{M}$, and $20 \mu \mathrm{M}$. Unstained control cultures were made for comparison of fluorescence; these received $50 \mu$ of T-broth instead of a dilution of dye. CellTracker ${ }^{\mathrm{TM}}$ CMTMR and CMFDA probes (Molecular Probes, Invitrogen) were also trialled (Herbert 2009), but as the BODIPY dyes were more effective, these results are not reported here.

Longevity of fluorescence. Cultures were checked 1 to $2 \mathrm{~h}$ after dyeing, and for up to $16 \mathrm{~d}$ after dyeing. Checks of cells dyed with 20, 0.2, and $0.1 \mu \mathrm{M}$ BODIPY FL, and 558/568 were discontinued after Days 2 $(0.2$ and $0.1 \mu \mathrm{M})$ and $3(20 \mu \mathrm{M})$, due to very weak fluorescence, non-fluorescence, or death of the culture. Cultures dyed with $2 \mu \mathrm{M}$ and $10 \mu \mathrm{M}$ BODIPY were checked at 2, 3, 6, 7, 10, 12, and 16 d after dyeing. At each check, cultures were examined and photographed under an epifluorescent compound microscope at 200 to $400 \times$ magnification (Optronics SN GH043774-H camera and MagnaFire 2.1 software). Paired photographs of $B d$ cells under bright field and fluorescence filters were taken to determine which 
parts of the cell were fluorescent. Fluorescence was checked under Olympus WIB (ex: 460 to $490 \mathrm{~nm}$; em: $>515 \mathrm{~nm}$ ) and WIY (ex: 545 to $580 \mathrm{~nm}$; em: $>610 \mathrm{~nm}$ ) filter sets. At least 3 cultures per concentration of each dye were examined for longevity. Additionally, differently dyed $B d$ cells were mixed together on a slide and viewed under the appropriate filter sets to determine if they could be discriminated from each other.

Growth inhibition. Standard procedures (RollinsSmith et al. 2002), with modifications, were used to test whether any concentration of dye inhibited $B d$ growth. $B d$ zoospores were stained with each of the dye concentrations. Un-dyed control zoospore cultures were made using the same methodology as for dyed cells, except $50 \mu \mathrm{l}$ of T-broth was added in place of dye at the dyeing step. Half of these un-dyed cultures were retained as positive controls. The other half were made into negative (zero-growth) controls immediately prior to experimentation by killing the cells via incubation in a water bath at $65^{\circ} \mathrm{C}$ for $>15$ min (Johnson et al. 2003). Aliquots $(100 \mu \mathrm{l})$ of zoospores from each treatment (5 dye concentrations, plus negative and positive controls) were placed into 10 wells of a 96 well flatbottomed, optically clear, microtiter plate (Greiner BioOne). Each $100 \mu \mathrm{l}$ aliquot consisted of $5 \times 10^{4}$ zoospores. Two microplates were made for each dye, with blank wells consisting of $100 \mu \mathrm{l}$ T-broth included on each plate.

Plates were covered with a lid and wrapped in plastic clingfilm to prevent loss of moisture. The optical density (OD, measured by absorbance) of each replicate was measured at a $490 \mathrm{~nm}$ wavelength using a plate reader (FLUOstar Omega, BMG LABTECH). Plates were read immediately after setup, and again after $8 \mathrm{~d}$ incubation at $23^{\circ} \mathrm{C}$. Plates were shaken briefly before each reading to resuspend cells. To check that the growth measured was from $B d$ and not from contamination of the microwells, $20 \mathrm{\mu l}$ from each microwell was plated onto T-plates at the end of the experiment and grown at $23^{\circ} \mathrm{C}$ for $7 \mathrm{~d}$.

Statistical analyses. Statistics were performed in SPSS v. 16 for Windows. The observed growth for each culture $(\triangle \mathrm{OD})$ was calculated as OD on Day 8 minus initial OD on Day 0. The effect of BODIPY FL and BODIPY 558/568 on $B d$ growth was evaluated with 1way ANOVA with Tamhane's T2 post-hoc tests, since the error variances were unequal. A treatment was considered to be inhibited if its average growth was lower than, and significantly different from, that of the positive control. If the average growth measured in a treatment was not significantly different from that of the negative control, it was considered to be completely inhibited. $\mathrm{p}$-values were considered significant at $\alpha=0.05$.

\section{RESULTS}

\section{Fluorescence}

Fluorescence became apparent in stained cultures $2 \mathrm{~d}$ after dyeing, presumably because cells had developed into thalli that were more easily seen and recognised as $B d$ cells under 200 to $400 \times$ magnification due to their larger size and clumping tendencies. Dyed thalli and zoosporangia were brightly fluorescent. Fluorescent zoospores were sometimes visible around the edge of clusters of encysted cells when the fluorescence produced was very bright, for example at Days 2 (BODIPY FL) and 16 (BODIPY 558/568). These dyes produced a granular appearance of fluorescence in the cytoplasm. Higher concentrations of dye produced the brightest and longest-lasting fluorescence. $B d$ cells dyed with $10 \mu \mathrm{M}$ BODIPY FL and 558/568 were still brightly fluorescent at Days 12 and 16, respectively. No or very weak fluorescence was observed at Day 2 in $B d$ cells dyed with $0.2 \mu \mathrm{M}$ and $0.1 \mu \mathrm{M}$ BODIPY FL and 558/568. Bright fluorescence was observed for cells dyed with $2 \mu \mathrm{M}$ BODIPY up to Day 6 (FL) and Day 10 (558/568), and thereafter weak fluorescence until Day 16.

$B d$ cells dyed with BODIPY FL and BODIPY 558/568 could be distinguished from each other by their fluorescence characteristics (Fig. 1). BODIPY 558/ 568-labelled cells could be distinguished by the presence of bright red fluorescence under the WIY filter (ex: 545 to $580 \mathrm{~nm}$; em: >610 nm) and yellow-orange fluorescence under the WIB filter (ex: 460 to $490 \mathrm{~nm}$; em: $>515 \mathrm{~nm}$ ) (Fig. 1A, B). BODIPY FL labelled cells produced weak red fluorescence under the WIY filter (Fig. 1A) and bright green fluorescence under the WIB filter (Fig. 1B). When $B d$ cells were difficult to locate on the slide due to low concentration, scanning the slide under the fluorescent filters proved to be a useful mechanism for locating both cell clusters and individual thalli or zoosporangia.

\section{Growth inhibition}

Staining $B d$ with $20 \mu \mathrm{M}$ of BODIPY 558/568 or FL appeared to inhibit cell growth, whereas growth was not affected at all other dye concentrations trialled. $B d$ dyed with $20 \mu \mathrm{M}$ of BODIPY 558/568 and FL had significantly inhibited growth (Tamhane T2 comparisons with positive control, FL: $p=0.003$, Fig. 2A; 558/568: $\mathrm{p}<0.001$, Fig. 2B). Staining $B d$ with $20 \mu \mathrm{M}$ of BODIPY FL partially inhibited $B d$ growth, as growth with this stain was significantly different from that of the negative control (Tamhane T2 comparison with negative control, BODIPY FL: $p=0.012$, Fig. 2A). However, staining $B d$ with $20 \mu \mathrm{M}$ of BODIPY 558/568 completely 

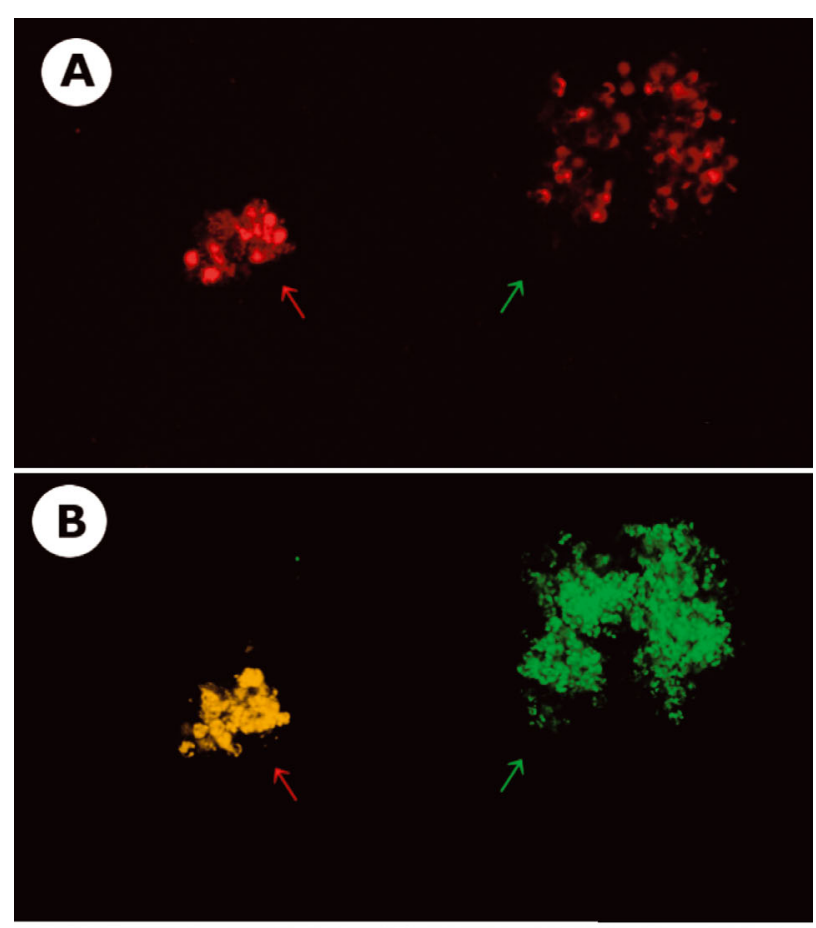

C
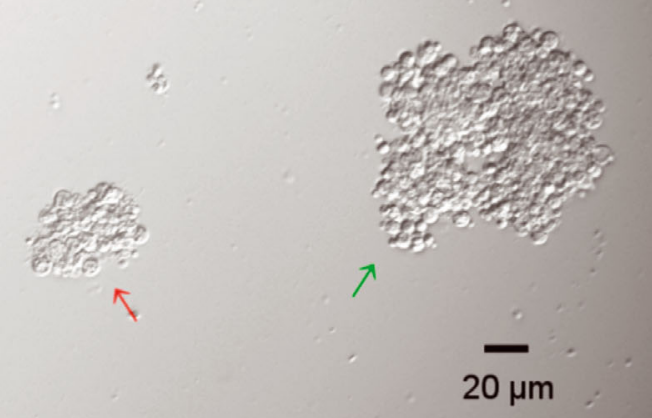

Fig. 1. Batrachochytrium dendrobatidis. A green arrow denotes the cluster is dyed with BODIPY FL, and a red arrow indicates BODIPY 558/568. (A) WIY filter set (excitation wavelength [ex]: 545 to $580 \mathrm{~nm}$; emission wavelength [em]: $610 \mathrm{~nm}$ ); (B) WIB filter set (ex: 500 to $520 \mathrm{~nm}$; em > $515 \mathrm{~nm}$ );

(C) as viewed under brightfield illumination

inhibited $B d$ growth (Tamhane T2 comparison with negative control, BODIPY 558/568: $p=0.799$, Fig. 2B). $B d$ growth was not inhibited at any of the other dye concentrations (BODIPY 558/568 and FL: Tamhane T2 comparisons with positive control, all $\mathrm{p}>0.050$ ).

\section{DISCUSSION}

The results indicate that the best combination for tracking $2 B d$ strains would be to use $10 \mu \mathrm{M}$ of both red-fluorescent BODIPY 558/568 and green-fluorescent BODIPY FL. Fluorescence performed best at a

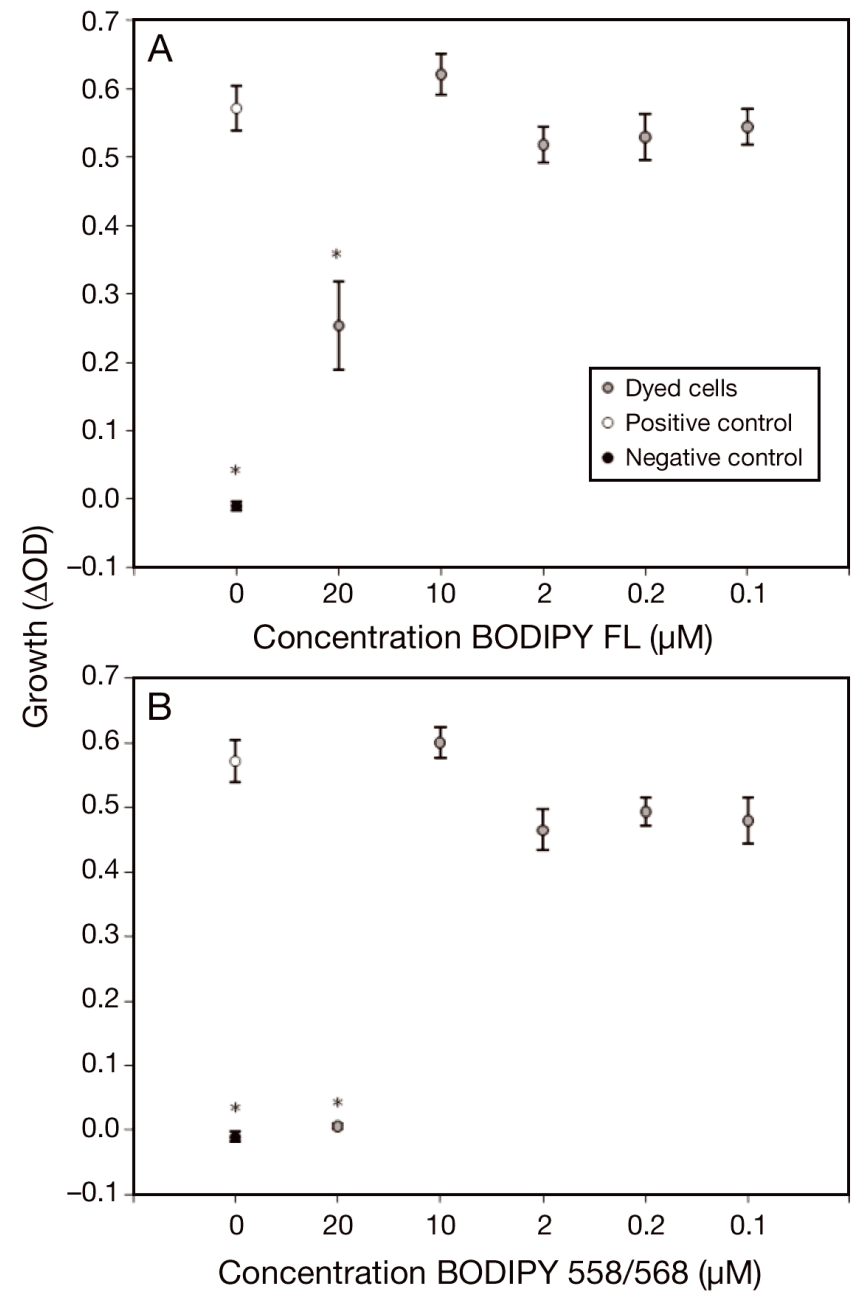

Fig. 2. Batrachochytrium dendrobatidis. Growth (change in optical density $[\Delta \mathrm{OD}]=\mathrm{OD}_{\text {Day8 }}-\mathrm{OD}_{\text {Day0 }}$ ) of zoospores dyed with selected concentrations of (A) green BODIPY FL dye and (B) red BODIPY 558/568 dye. All $n=20$. Error bars are \pm 1 SE. ${ }^{*}$ Significant difference from the positive control $(p<0.05)$

$10 \mu \mathrm{M}$ concentration, labelling cells for at least 12 to $16 \mathrm{~d}$, and this concentration did not inhibit $B d$ growth.

The dyes appear to be heritable by daughter cells, since the fluorescence lasted for at least 2 life cycles, which take 4 to $5 \mathrm{~d}$ to complete at $23^{\circ} \mathrm{C}$ (Berger et al. 2005a). Additionally, several fluorescent zoospores were observed at the edges of zoosporangia clusters 2 and $16 \mathrm{~d}$ after dyeing. It is extremely unlikely that these zoospores were those that were originally dyed, since $B d$ zoospores typically encyst within $24 \mathrm{~h}$ (Piotrowski et al. 2004, Berger et al. 2005a). Presumably zoospores inherit labelled lipids from parent cells during the mitotic division of the parent thallus (Berger et al. 2005a). The grainy appearance of the BODIPY fluorescence in thalli and zoosporangia suggests that these probes are being incorporated into the numerous 
lipid globules at the periphery of the core of aggregated ribosomes in zoospores and thalli (Berger et al. 2005a).

The BODIPY dyes appear to be potentially suitable for tracking the growth and development of $B d$ strains over 3 to 4 life cycles, as bright fluorescence could be achieved for at least 12 to $16 \mathrm{~d}$. This suggests that the longevity of these dyes should be suitable for distinguishing and comparing the growth of different strains in culture over time. It is also possible that this technique could be used in conjunction with flow cytometry for cell quantfication or confocal microscopy.

In summary, the present study indicates that the best combination for labelling and tracking $2 B d$ strains would be to use $10 \mu \mathrm{M}$ of BODIPY FL and 558/568 dyes. The longevity displayed by these dyes suggests that they might be suited to tracking the development of different $B d$ strains in culture, either in isolation or in the presence of another strain.

Acknowledgements. The authors thank the members of The Frog Research Group at the University of Otago for their helpful comments on the manuscript. We thank D. Keeney, R. Poulin, and K. Beggs for providing BODIPY dye and microwell plates. K. Judge provided invaluable technical support. We also thank R. Poulter and M. Butler for providing the initial $B d$ cultures, R. Speare for his advice, and P. Dearden for arranging access to the epifluorescent microscope. This project was funded by a University of Otago Postgraduate Award to S.M.H. and the University of Otago Zoology Department graduate student fund.

\section{LITERATURE CITED}

Bell AS, De Roode JC, Sim D, Read AF (2006) Withinhost competition in genetically diverse malaria infections: parasite virulence and competitive success. Evolution 60: 1358-1371

Berger L, Speare R, Daszak P, Green DE and others (1998) Chytridiomycosis causes amphibian mortality associated with population declines in the rain forests of Australia and Central America. Proc Natl Acad Sci USA 95: 9031-9036

> Berger L, Hyatt AD, Speare R, Longcore JE (2005a) Life cycle stages of the amphibian chytrid Batrachochytrium dendrobatidis. Dis Aquat Org 68:51-63

Berger L, Marantelli G, Skerratt LF, Speare R (2005b) Virulence of the amphibian chytrid fungus Batrachochytrium dendrobatidis varies with the strain. Dis Aquat Org 68: 47-50

Boyle DG, Hyatt AD, Daszak P, Berger L and others (2003) Cryo-archiving of $B d$ and other chytridiomycetes. Dis Aquat Org 56:59-64

Buckling A, Brockhurst MA (2008) Kin selection and the evolution of virulence. Heredity 100:484-488

de Roode JC, Pansini R, Cheesman SJ, Helinski MEH and others (2005) Virulence and competitive ability in genetically diverse malaria infections. Proc Natl Acad Sci USA 102:7624-7628

Fisher MC, Bosch J, Yin Z, Stead DA and others (2009) Proteomic and phenotypic profiling of the amphibian patho- gen Batrachochytrium dendrobatidis shows that genotype is linked to virulence. Mol Ecol 18:415-429

Goka K, Yokoyama J, Une Y, Kuroki T and others (2009) Amphibian chytridiomycosis in Japan: distribution, haplotypes and possible route of entry into Japan. Mol Ecol 18:4757-4774

Herbert SM (2009) Novel approaches for elucidating drivers of Batrachochytrium dendrobatidis epidemiology in amphibians. MSc thesis, University of Otago, Dunedin

James TY, Litvintseva AP, Vilgalys R, Morgan JAT and others (2009) Rapid global expansion of the fungal disease chytridiomycosis into declining and healthy amphibian populations. PLoS Pathog 5:e1000458

Johnson M, Berger L, Phillips L, Speare R (2003) Fungicidal effects of chemical disinfectants, UV light, desiccation and heat on the amphibian chytrid Batrachochytrium dendrobatidis. Dis Aquat Org 57:255-260

Keeney DB, Lagrue C, Bryan-Walker K, Khan N, Leung TLF, Poulin R (2008) The use of fluorescent fatty acid analogs as labels in trematode experimental infections. Exp Parasitol 120:15-20

Kurtz J, van der Veen IT, Christen M (2002) Fluorescent vital labelling to track cestodes in a copepod intermediate host. Exp Parasitol 100:36-43

> Lagrue C, McEwan J, Poulin R, Keeney DB (2007) Cooccurences of parasite clones and altered host phenotype in a snail-trematode system. Int J Parasitol 37:1459-1467

Leung TLF, Poulin R, Keeney DB (2009) Accumulation of diverse parasite genotypes within the bivalve second intermediate host of the digenean Gymnophallus sp. Int J Parasitol 39:327-331

> Leung TLF, Keeney DB, Poulin R (2010) Genetics, intensitydependence, and host manipulation in the trematode Curtuteria australis: following the strategies of others? Oikos 119:393-400

> Lips KR, Diffendorfer J, Mendelson JR, Sears MW (2008) Riding the wave: reconciling the roles of disease and climate change in amphibian declines. PLoS Biol 6(3):e72

Marantelli G, Berger L, Speare R, Keegan L (2004) Changes in distribution of Batrachochytrium dendrobatidis and keratin during tadpole development leading to high mortality after metamorphosis. Pac Conserv Biol 10:173-179

> Massey RC, Buckling A, Ffrench-Constant R (2004) Interference competition and parasite virulence. Proc Biol Sci 271: 785-788

Molecular Probes (2008) Celltracker ${ }^{\mathrm{TM}}$ probes for long-term tracing of living cells. Molecular Probes, Inc., Invitrogen, Carlsbad, CA

Morehouse EA, James TY, Ganley ARD, Vilgaly R, Berger L, Murphy PJ, Longcore JE (2003) Multilocus sequence typing suggests the chytrid pathogen of amphibians is a recently emerged clone. Mol Ecol 12:395-403

Morgan JAT, Vredenburg VT, Rachowicz LJ, Knapp RA and others (2007) Population genetics of the frog-killing fungus Batrachochytrium dendrobatidis. Proc Natl Acad Sci USA 104:13845-13850

Piotrowski JS, Annis SL, Longcore JF (2004) Physiology of Batrachochytrium dendrobatidis, a chytrid pathogen of amphibians. Mycologia 96:9-15

Råberg L, de Roode JC, Bell AS, Stamou P, Gray D, Read AF (2006) The role of immune-mediated apparent competition in genetically diverse malaria infections. Am Nat 168: $41-53$

> Read AF, Taylor LH (2001) The ecology of genetically diverse infections. Science 292:1099-1102

- Rollins-Smith LA, Carey C, Longcore J, Doersam JK, Boutte A, Bruzgal JE, Conlon JM (2002) Activity of antimicrobial 
skin peptides from ranid frogs against Batrachochytrium dendrobatidis, the chytrid fungus associated with global amphibian declines. Dev Comp Immunol 26:471-479

Skerratt LF, Berger L, Speare R, Cashins S and others (2007) Spread of chytridiomycosis has caused the rapid global decline and extinction of frogs. EcoHealth 4:125-134

Stockwell MP, Clulow J, Mahony MJ (2010) Efficacy of SYBR 14/propidium iodide viability stain for the amphibian chytrid fungus Batrachochytrium dendrobatidis. Dis Aquat Org 88:177-181

Editorial responsibility: Cynthia Carey,

Boulder, Colorado, USA
Voyles J, Young S, Berger L, Campbell C and others (2009) Pathogenesis of chytridiomycosis, a cause of catastrophic amphibian declines. Science 326:582-585

Walker SF, Bosch J, Gomez V, Garner TWJ and others (2010) Factors driving pathogenicity vs. prevalence of amphibian panzootic chytridiomycosis in Iberia. Ecol Lett 13: $372-382$

Weldon C (2005) Chytridiomycosis, an emerging infectious disease of amphibians in South Africa. PhD thesis, NorthWest University, Potchefstroom

Submitted: August 12, 2010; Accepted: May 26, 2011

Proofs received from author(s): August 26, 2011 